\title{
OPTIMIZACIÓN DE RECURSOS HÍDRICOS Y ARMONIZACIÓN DE SUS USOS: EL CONSORCIO DE AGUAS DE LA MARINA BAJA
}

\author{
Antonio Gil Olcina \\ Instituto Interuniversitario de Geografía \\ Universidad de Alicante
}

\section{RESUMEN}

En la Marina Baja, comarca alicantina de la seca región climática del Sureste Ibérico, el difícil desafío de conjugar el extraordinario desarrollo turístico y urbano de su franja litoral, que polariza Benidorm, con disponibilidades hídricas exiguas e irregulares, ha requerido un conjunto de actuaciones del mayor interés, para la optimización de éstas y la armonización de sus usos, protagonizadas por el Consorcio de Aguas de la Marina Baja.

Dichas iniciativas incluyen: mayor y mejor regulación de recursos epigeos, potenciación sostenible de los subterráneos, y reutilización de aguas depuradas, con superposición de dos sistemas independientes - aguas blancas y depuradas - , que funcionan al unísono; sin que falte, para conjurar el riesgo extremo de una sequía prolongada e intensa, la posibilidad de emplear caudales foráneos.

Palabras clave: Marina Baja, Consorcio de Aguas, reutilización aguas depuradas, caudales foráneos.

\section{RÉSUMÉ}

Dans la Marina Baja, contrée d'Alicante située dans la région sèche du Sud-est Ibérique, le difficile défi de conjuguer l'extraordinaire développement touristique et urbain de sa bande littorale, concentré à Benidorm, avec des disponibilités hydriques exiguës et irrégulières, a supposé un ensemble d'interventions du plus grand intérêt sur leur maximisation et l'harmonisation de leurs utilisations, actions menées par le Consortium des Eaux de la Marina Baja).

Ces initiatives comprennent: un plus fort et meilleur contrôle des ressources épigées, un développement soutenable des ressources souterraines et une réutilisation des eaux épurées, avec la superposition de deux systèmes indépendants - eaux blanches et eaux épurées - , qui fonctionnent à l'unisson; sans qu'il manque, pour conjurer le risque extrême d'une sécheresse prolongée et intense, la possibilité d'utiliser des cours d'eau étrangers.

Mots clés: Marina Baja, Consortium des Eaux, réutilisation des eaux épurées, cours d'eau étrangers. 


\section{ABSTRACT}

The Marina Baja district in Alicante province, in the dry climate region of the southeastern part of the Iberian Peninsula, faces the difficult challenge of having to combine extraordinary levels of growth in tourism and urban development along the area's coastline, particularly around Benidorm, with exiguous and irregular availability of water resources, requiring the Marina Baja Water Consortium to implement several major initiatives to optimise how the area's water resources are used.

These initiatives include increased and improved regulation of ground resources, sustainable optimisation of subterranean resources, and reusing reclaimed water. Two independent systems operate at the same time, using white water and reclaimed water, and water from outside the area can also be used if needed to ward off the extreme risk of a prolonged, intense period of drought.

Key words: Marina Baja, Water Consortium, reusing reclaimed water, water from outside the area.

Mediado el siglo XIX, el Diccionario Geográfico-Estadístico-Histórico de P. Madoz proporcionaba del núcleo de Benidorm, entre otros, los datos siguientes: «...su suelo es algun tanto desigual, y las calles bastante anchas por lo regular, siendo la mejor la llamada de la Alameda, que extendiéndose desde la parr. hasta la salida del pueblo hacia Polop, forma un conjunto hermoso por su grande anchura y por la regularidad de las casas que como cuasi todas las del pueblo, en número de unas 900, son nuevas, espaciosas y ventiladas, constando generalmente de un solo piso y boardillas, llamadas en aquellos pueblos porchins ó graneros, por ser este el uso á que están destinadas. Tiene casa de ayunt., cárcel pública ... una igl. bastante capaz, dedicada á Santiago, ... para surtido de los vec. tiene 3 fuentes dentro de la v., y por la escasez que muchas veces han sentido de tan necesario art., tratan de conducir ciertas aguas que nacen en las heredades del Liriet, casi al N. de dicho pueblo y media leg. de él aproximadamente ..... Aunque todo el terreno es calcinoso, de greda arenisca y naturalmente estéril, han sabido, no obstante, los hab. de Benidorm, reducir á frondosas huertas sus dos terceras partes por medio del continuo y perseverante trabajo, el frecuente abono y la construcción de cerca de 200 norias que suministran abundantes aguas. Una acequia que toma su curso desde las fuentes de Polop, pasando por Nucía y Alfaz, se introduce en su térm. y fertiliza tambien una parte del mismo, que ademas se encuentra plantado de almendros, algarrobos, moreras y árboles frutales ... Las prod. mas comunes son almendra, algarrobas, cebada, maiz, trigo, pasas, vino, y toda clase de frutas y verduras ... Ademas de algunos oficios mecánicos que ocupan á muy contadas personas, se ejercitan principalmente los vec. de esta v. en la pesca, de que es muy abundante su costa y el islote; por su grande inteligencia en las almadrabas que se usan para coger los atunes, son ellos los que arman cuasi todas las de la Península, y en la misma desembocadura del r. Torres tienen calada una, que es bastante abundante en esta clase de pescado. Su matricula de mar es numerosa, y una multitud de embarcaciones de mas o menos cala dan ocupación continua á todos sus marineros, que por su carácter particular y por su genio marino se emplean muchísimos de ellos en el servicio de guarda-costas sin que por eso falten algunos arrieros que se ocupan diariamente en el transporte de pescado para el interior del reino de Valencia. Tambien se encuentran 3 molinos harineros, 3 de aceite, una fáb. de espartería y otra de lonas para los buques. El comercio es de alguna consideración si se tiene en cuenta, por otra parte, que la aduana es solo de cuarta clase; se reduce generalmente á la importación de 
cereales de Andalucía, para surtir los pueblos del interior, y a la extracción de espartería labrada, pasas, almendras, algarrobas y demas frutos sobrantes del país «(IV, págs. 212213). Se indicaba asimismo una población de 805 vecinos, 4.502 almas.

Cien años después, la morfología urbana de Benidorm apenas había cambiado, ni tampoco su realidad socioeconómica. Perteneciente a la comarca de la Marina Baja $\left(751,34 \mathrm{~km}^{2}\right)$ y situada en la seca región geográfica del Sureste Ibérico, partícipe de los inconvenientes y posibilidades inherentes a esta ubicación, con el problema del agua muy en primer término, continuaba siendo la misma pequeña villa agrícola y marinera; además, en este largo intervalo, el municipio había perdido población: 4.502 almas en 1840 y sólo 4.159 para 1960; así pues, la emigración había más que consumido el crecimiento vegetativo. A favor de un conjunto de hechos en muy diferentes escalas, entre la internacional y local, el panorama se transformaría por completo en el tercer cuarto del siglo XX, ocasionando un fortísimo incremento demográfico: los habitantes de 1960 se habían más que duplicado en 1970 (10.714) y sextuplicado, con creces, al lustro siguiente (26.400 en 1975). Unos años más tarde, Rosselló escribía: «L'especularitat del fenomen converteix Benidorm en espill del desenvolupament residencial i de l'oci, en capital turistica del País Valenciá» (Rosselló, 55 ciutats valencianes, 1984, pág. 197); en efecto, el turismo había sido causa única y exclusiva de la mutación urbana y socioeconómica de Benidorm. El desarrollo de dicha actividad fue vertiginoso, como sintetizan estas cifras: 52 hoteles (2.700 plazas) en 1961; 87 (6.300 plazas), con más de 40.000 plazas en apartamentos y 2.500 en campings, para 1969; y en 1976 las plazas hoteleras subían a 31.000 , y a 50.000 y 3.000 las de apartamentos y campings respectivamente. Para este último año, se estimaba una población flotante y mudadiza cada 10-15 días de 84.000 personas, que ascendería a las 200.000 en fechas punta, además de los residentes más estables de chalets y bungalows.

Como se ha dicho, esta eclosión turística, que trocó el veraneo tradicional de un limitado número de familias de L'Alcoià, a las que se sumaron luego madrileñas de clase media, en la atracción masiva de turistas de Europa Occidental y Nórdica, se benefició de una serie de factores, y fue posible por su conjunción. Algunos de orden internacional, como la recuperación tras la dura postguerra mundial y el fin del aislamiento internacional de España (Acuerdos con EE.UU. e ingreso en la ONU); de carácter nacional, Plan de Estabilización y moneda convertible; provincial, apertura del aeropuerto de El Altet,y, a la hora de puesta en valor de la excepcional oferta de sol y playa de Benidorm, la singular y dinámica personalidad del entonces Alcalde, Pedro Zaragoza Orts, que impulsaría, con decisión y fuerza, el nuevo planteamiento, presente ya en el Plan General de Ordenación Urbana de 1956; por otra parte, pronto desbordado.

A los efectos que ahora interesan, resultaba obligado, con la referida evolución, el crecimiento exponencial de la demanda de agua para abastecimiento urbano, que se convirtió en problema esencial, cuya gravedad pondrían ampliamente de manifiesto los años secos, como 1969, y, sobre todo, la dura y prolongada sequía de 1978-84, que acicatearía poderosamente la búsqueda de una solución adecuada.

\section{Disponibilidad y demanda de agua: el abastecimiento de Benidorm (1950-1975)}

Sin duda, resulta harto significativo que el primer depósito municipal de aguas claras entrara en servicio el año 1960; hasta fecha tan tardía el abastecimiento de Benidorm se articulaba sobre la red de riego mediante una serie de canalillos que tomaban agua de la conducción de riego, procedente de Polop, y la llevaban a las cisternas de las viviendas unifamiliares; en cada aljibe, una anguila hacía, a un tiempo, de depurador biológico e 
indicador fiable de la aptitud de aquélla para consumo. De la precariedad del suministro habla que, en estiaje, el caudal del pozo Rabasa (Polop) no subiera de 35 l/s y también que el de Golondro, en la partida benidormí de Armanello, como suplemento y apoyo, en idéntica situación, no pasara de 20 1/s (46 en invierno) y con problemas de intrusión marina. Cinco años después, las gestiones del Ayuntamiento se tradujeron en una concesión sobre el agua embalsada en Guadalest, que, acorde con la marcada estacionalidad existente entonces en la demanda turística, era de 90 1/s en julio-agosto, 60 junio y septiembre y bajaba a 30 el resto del año (GAVIRIA, M. et ALII: Benidorm, ciudad nueva, 1977, pág. 448).

Las dificultades de abastecimiento en el año hidrológico de 1968-69, muy seco, hicieron patente la urgencia de elevar y almacenar en el embalse de Guadalest el caudal de las Fuentes del Algar, remodelando a dicho efecto el esbozado Consorcio de la Marina Baja; además, se estimó necesaria la conexión directa del referido reservorio con un nuevo depósito municipal, para abastecer a 200.000 personas. El 20 de octubre de 1969 la Dirección General de Obras Hidráulicas convocó concurso de proyectos a dicho efecto; y, el 6 de mayo siguiente, se informó, a los alcaldes de los municipios interesados, que éstos habían de asumir el 65\% (147.550.000 pesetas) del coste para conseguir un caudal total de 1.000 1/s, más de la mitad $(590,98)$ para Benidorm, con una aportación de 87.198.243 pesetas. Casi un año después, el Consejo de Ministros adjudicó el concurso en 226.895 .902 pesetas. Las obras debían concluir en un año, pero tardaron más de cinco. Con anterioridad, el Ministerio de Gobernación autorizó, el 16 de octubre de 1974, la constitución del Consorcio de Abastecimiento de Aguas de la Marina Baja. A comienzos de 1976, la estación de bombeo de las Fuentes de Algar no había entrado aún en funcionamiento; y tampoco las tuberías de descenso desde el embalse de Guadalest a los depósitos de Benidorm, con repetidas roturas, lo hacían con la necesaria normalidad.

Además, por entonces, se hizo notar que «aun existiendo la estación de bombeo y suponiendo que funcionase perfectamente, en el momento en que lleguen ciclos secos que duren 2 ó 3 años ( $\sin$ que se trate de sequías catastróficas) no habrá agua suficiente para los riegos del Algar, Benidorm y el resto de municipios consorciados en la Marina Baja, por lo que se habrá de comenzar a buscar otros recursos ...» (GAVIRIA, M. et ALII: Benidorm, ciudad nueva, 1977, pág. 459). Sin duda, ésta era la opinión de Jose Ramón García Antón, Ingeniero de Caminos, Jefe de los Servicios de Ingeniería del Ayuntamiento de Benidorm, «con el que hemos colaborado estrechamente para la redacción de este informe». Entre las recomendaciones formuladas en el mismo figuraban las siguientes: Reorganización de la gestión del agua en riego y abastecimiento. Estudio sistemático y exhaustivo de aguas subterráneas en la Marina Baja. Puesta en funcionamiento real del Consorcio de Abastecimiento de Aguas de la Marina Baja, con la inmediata entrada en servicio de la estación elevadora de las Fuentes del Algar al pantano de Guadalest. Construcción de la tubería de conducción del pantano de Guadalest a la Rompuda. Incorporación al Consorcio de Abastecimiento de la Marina Baja del embalse de Amadorio. Construcción de un nuevo Canal Bajo del Algar paralelo al anterior según idea y avance de presupuesto elaborado por José Ramón García Antón, por importe de unos 300 millones de pesetas. Bombeo del agua de las Fuentes del Algar al pantano del Amadorio a través de la prolongación, desde el río Torres, del Canal Bajo del Algar; se pretendía con ello el almacenamiento del agua de las Fuentes del Algar en el pantano del Amadorio con una elevación de unos $80 \mathrm{~m}$, ya que el bombeo al de Guadalest casi triplica esta altura. Estudio de un nuevo Canal Alto del Algar que desde las Fuentes circule por la cota 115 con mínima pendiente. Construcción de una estación depuradora de aguas residuales para Benidorm que reciclase el agua una vez depurada y la elevase a la cota 70 del Canal Bajo 
del Algar actual, para ser empleada en riego. Se consideraba asimismo el bloqueo del crecimiento de la construcción en toda la Mariana Baja, al menos hasta que no entrase en servicio la estación de bombeo de las Fuentes del Algar, al tiempo que se proponía desestacionalizar la demanda turística, potenciando la de invierno.

Con referencia al período 1956-75, el mencionado Informe señalaba que «la escasez de agua en Benidorm y la gestión de recursos hidráulicos ha sido una obsesión permanente en los últimos 20 años. En general, el abastecimiento se ha resuelto hasta ahora satisfactoriamente, excepto en el año 1969, y los problemas graves se van a plantear a partir de 1975-76». Todavía este último año no se había producido la constitución del Consorcio de Abastecimiento de Aguas de la Marina Baja.

\section{Consorcio para Abastecimiento de Aguas y Saneamiento de la Marina Baja}

En escritura pública de 28 de octubre de 1977 quedó constituido el Consorcio para Abastecimiento de Aguas y Saneamiento de la Marina Baja, al amparo del art. 101, apartados a) y c), de la Ley de Régimen Local y del art. 37 del Reglamento de Servicios de las Corporaciones Locales de 17 de junio de 1955. Su naturaleza es la de entidad jurídica pública local de carácter asociativo e institucional. Miembros del Consorcio eran, y, salvo Callosa d'En Sarriá, son la Diputación Provincial de Alicante, la Confederación Hidrográfica del Júcar y los Ayuntamientos de Alfaz del Pí, Altea, Benidorm, Callosa d'Ensarriá, Finestrat, Polop, La Nucía y Villajoyosa. En principio, y sin perjuicio que le pudiesen ser atribuidos otros servicios de interés local, los fines del Consorcio eran los siguientes: estudio de las necesidades de abastecimiento de aguas y saneamiento de la Marina Baja; elaboración, con la colaboración de la Confederación Hidrográfica del Júcar, de los planes para aprovechamiento de las aguas y saneamiento de la expresada comarca; redacción de estudios, anteproyectos y proyectos que satisfagan dichas necesidades; solicitud de concesiones o autorizaciones para abastecimiento de aguas, y tratamiento y vertido de las residuales; realización de obras e instalaciones para tratamiento de aguas, evacuación, depuración, vertido y aprovechamiento de residuales; explotación y conservación de esas instalaciones; y, por último, el Consorcio había de coordinar sus actividades y, en su caso, las de los Ayuntamientos indicados con las del Ministerio de Obras Públicas. Para ello, los Ayuntamientos consorciados asumían el oportuno compromiso de coordinación; y, de no existir acuerdo, el asunto se sometería a la consideración resolutoria de los Ministerio de Obras Públicas y de la Gobernación.

Aunque el art. 10 del Estatuto del Consorcio disponía que «será Presidente del Consorcio el Gobernador Civil de la Provincia», señalaba también que «podrá delegar expresamente en el Presidente de la Diputación Provincial»; y esta posibilidad se convirtió en uso desde el comienzo, al punto que el referido Estatuto, publicado en el Boletín Oficial de la Provincia de Alicante de 10 de noviembre de 1977, ya fue suscrito como presidente por el de la Diputación Provincial, entonces el alcoyano Jorge Silvestre Andrés. Órganos de gobierno unipersonales, además del presidente, eran, en su caso, tres vicepresidente, por este orden: Presidente de la Diputación, Ingeniero Director de la Confederación Hidrográfica del Júcar y Alcalde de Benidorm. Por su parte, los colegiados eran la Junta General (presidente, vicepresidentes, alcaldes de los ayuntamientos consorciados, ingeniero encargado de la Sección de la Confederación que tenga a su cargo el territorio en que radica el Consorcio, un representante de cada una de las Corporaciones Locales señaladas, así como, con voz y sin voto, un Secretario y un Interventor) y la Comisión Permanente, donde los representantes de los entes locales consorciados se reducían sólo a tres, elegidos por la Junta General. En cuanto al voto en ésta, el Art. 22.1 precisaba que los entes integrantes del Consorcio 
tendrían dos clases de votos: uno representativo, igual para todos, y otro proporcional al porcentaje que supusiera la aportación de cada municipio, con el reparto siguiente:

\begin{tabular}{|l|c|c|c|c|}
\hline $\begin{array}{c}\text { Entes } \\
\text { Consorciados }\end{array}$ & Aportaciones & $\begin{array}{c}\text { Votos } \\
\text { representativos }\end{array}$ & $\begin{array}{c}\text { Votos } \\
\text { proporcionales }\end{array}$ & Total votos \\
\hline Benidorm & $59,09 \%$ & 2 & 5,909 & 7,909 \\
\hline Altea & $13,60 \%$ & 2 & 1,360 & 3,360 \\
\hline Villajoyosa & $14,68 \%$ & 2 & 1,468 & 3,468 \\
\hline Alfaz del Pi & $4,29 \%$ & 2 & 0,429 & 2,429 \\
\hline Polop & $1,00 \%$ & 2 & 0,100 & 2,100 \\
\hline La Nucía & $3,65 \%$ & 2 & 0,365 & 2,365 \\
\hline Callosa de Ensarriá & $2,87 \%$ & 2 & 0,287 & 2,287 \\
\hline Finestrat & $0,78 \%$ & 2 & 0,078 & 2,078 \\
\hline Diputación & - & 2 & - & 2,000 \\
\hline Confederación & - & 2 & - & 2,000 \\
\hline Presidente & - & 1 & - & 1,000 \\
\hline
\end{tabular}

En cuanto a la financiación del Consorcio, los Ayuntamientos integrantes del mismo, asumieron la obligación de abonarle los volúmenes de agua consumidos a los precios acordados; y, para ello, otorgaron a favor de aquél poder suficiente para que «pueda percibir de la Delegación de Hacienda y con cargo a las cantidades liquidadas por la misma a favor de las Entidadas locales, los importes que éstas no hubieran satisfecho al Consorcio, en el plazo máximo de un mes a partir del requerimiento que a tal efecto les formule»; y, en este mismo orden, el Consorcio establecería, en cada caso, el medio de garantizar el pago de los usuarios directos distintos de aquéllas, es decir, las personas físicas o jurídicas con autorización de aquél «para realizar las acometidas inmediatas a los ramales de suministros o depósitos de agua potable, o a las redes o instalaciones de saneamiento, propiedad del Consorcio» (art. 44.1).

Aspectos asimismo de máxima relevancia eran los relativos a titularidad de las concesiones y a los repartimientos de agua, regulados en los arts. 45 y 46 del Estatuto respectivamente. El Consorcio es titular de la concesiones de agua que se le otorguen para el abastecimiento común; y expresamente se indicó que haría uso de la reserva de 1.500 l/s existente a favor de la Confederación Hidrográfica del Júcar para abastecimiento de los municipios de Alfaz del Pí, Altea, Benidorm, Callosa de Ensarriá, Finestrat, Polop, La Nucía y Villajoyosa. En cambio, los derechos de aprovechamiento de aguas de que disfrutasen dichos ayuntamientos con anterioridad a la constitución del Consorcio o los que obtuviesen con posterioridad, «subsistirán en todos sus términos, sin perjuicio de que las citadas Corporaciones puedan acordar la incorporación de los mismos al Consorcio».

Por lo que hace al aprovechamiento, todos los usuarios directos ostentan derecho al de un caudal de agua determinado por la disponibilidad del Consorcio, la de concesiones o propiedades de aquéllos y las necesidades previstas en cada núcleo urbano, con prioridad en todo caso del uso doméstico. Cuando a juicio de la Junta General, asesorada por la Confederación Hidrográfica del Júcar, existiese suficiente caudal para el abastecimiento de la zona, las Entidades Beneficiarias pueden consumir libremente los caudales precisos. Y si fuese preciso determinar caudales, el asignado a cada usuario directo será «el máximo 
disponible a los efectos de abastecimiento de sus núcleos principales de población, dentro de cada término municipal, respetando siempre sus propias concesiones» (art. 47). Es de notar la existencia en el Estatuto de una sola disposición adicional, por la cual se limitaba la participación inicial del Ayuntamiento de Finestrat al abastecimiento de su franja costera, sin perjuicio de que, tras los estudios y actuaciones pertinentes, el Consorcio pudiese acordar, en su momento, el del resto del término.

Publicado el 10 de noviembre de 1977 en el Boletín Oficial de la Provincia de Alicante, el Estatuto entró en vigor antes de la prolongada sequía de 1978-84, que supondría momento decisivo en la búsqueda de una solución adecuada. En efecto, sería este episodio, que requirió el abastecimiento de agua a Benidorm mediante buques-tanque, la causa inmediata de un conjunto de acuerdos y actuaciones que, por la eficacia de los mismos, su armonía intrínseca y las realizaciones que los permiten, han hecho del Consorcio una institución modélica, capaz de solventar el serio desafío del suministro de agua a Benidorm y a los restantes municipios consorciados.

\section{Alternativa extrema en el verano-otoño de 1978: transferencia naval o «cierre» de Benidorm}

La comarca alicantina de la Marina Baja es parte de la región geográfica del Sureste Ibérico, la más seca de la Península y Europa, con un régimen de lluvias escasas, irregulares e intensas, que conjuga duras y prolongadas sequías con esporádicos diluvios. Por su carácter de sotavento frente a la circulación general del oeste, cercanía a la subsidencia subtropical, vecindad del Sahara, posición retraída en la cuenca del Mediterráneo Occidental y amplia incidencia del relieve, que determina efecto foehn sobre el flujo del oeste y abrigo, con disimetría pluviométrica, respecto de las borrascas atlánticas, la región geográfica del Sureste es la más expuesta de la Península al riesgo natural de las sequías. Tampoco el trazado de la costa es ajeno a la escasez de precipitaciones; ejemplo prototípico constituye el cambio de rumbo del litoral al sur del cabo de al Nao, que, al trocar el de NE-SW por NW-SE, resguarda de los temporales del noreste, y motiva que, con pocos kilómetros de distancia, los volúmenes de precipitación anual media del Marquesat (Denia, $674 \mathrm{~mm}$ ) se reduzcan a la mitad en la Marina Baja (Benidorm, 344).

Seco el bienio precedente, en marzo de 1978 la situación era tan seria como para que el Ayuntamiento de Benidorm acordase drásticas restricciones en el suministro de agua, contraído a sólo 7 horas diarias; simultáneamente, se intensificaron las gestiones, sobre todo en el Ministerio de Obras Públicas, para urgir soluciones. Como inmediata, se resolvió recurrir a la explotación del Pozo San Vicente, en el Acuífero de Polop, que suponía un aporte adicional, insuficiente a todas luces, de $40 \mathrm{l} / \mathrm{s}$. Y con un abastecimiento tan extremadamente precario, en el ápice de la temporada turística, se aguantó a duras penas hasta 20 de agosto, fecha en que el nivel de las reservas casi inexistentes del embalse de Guadalest quedó por bajo de la galería de toma, y se hizo precisa la instalación de bombas sumergibles para extraer los últimos metros cúbicos. Fácil es imaginar, no tanto reproducir, un clamor ciudadano continuo y creciente, al que no tardaron en sumarse cancelación de vuelos turísticos y anulación de reservas. En síntesis, agotada la reserva de Guadalest, el angustioso balance en el principal núcleo turístico valenciano era el siguiente: las disponibilidades hídricas se limitaban a 60-80 1/s de agua potable y otros 100 de elevada salinidad; y sobre este exiguo volumen gravitaba una demanda, por lo que restaba de agosto, de 500 1/s, que bajaría a 400 en septiembre y a 300-250 1/s para octubre.

A principios de septiembre, en el Ministerio de Comercio y Turismo, el gravísimo problema, extremadamente perentorio, se concretó en un dilema rotundo e inapelable: 
transferencia naval de recursos hídricos o interrupción de la actividad turística («cierre») de Benidorm. Acto seguido, autoridades preautonómicas y locales consideraron que, a pesar de las dificultades de todo tipo, técnicas y financieras, era necesario instrumentar inmediatamente los referidos trasvases, a través de buques-tanque, desde la red en alta de Aguas Municipalizadas de Alicante, servida primordialmente por la Mancomunidad de los Canales del Taibilla. A dicho efecto, mientras Gobierno Civil recibía la conformidad de ambas entidades, la Dirección General de Transportes Marítimos, a tenor dela información recibida, consideró la idoneidad de Naviera Ibérica, S.A. para prestar dicho servicio. Este puente naval Alicante-Benidorm requería disponer de las necesarias instalaciones de carga y descarga: la primera consistía básicamente en una conducción de $300 \mathrm{~mm}$ de diámetro y $3 \mathrm{~km}$ de longitud entre El Palmeral y el Muelle II del Puerto de Alicante; más compleja era la segunda, en Benidorm, con conducciones marina (575 m y diámetro $300 \mathrm{~mm}$ en acero, y otros $500 \mathrm{~m}$ de conducción flexible de $300 \mathrm{~mm})$ y en tierra $(1.716 \mathrm{~m}$ de $500 \mathrm{~mm}$ y 336 de 315), a las que era preciso sumar Manifold submarino, campos de boyas y estación de fondeo y atraque. El 3 de octubre de 1978 estuvieron listas dichas instalaciones, y asimismo los buques-tanque «Juan de Cardona» (5.000 Tm) y «Luis de Requesens» (5.100 $\mathrm{Tm}$ ) quedaron a disposición del Ayuntamiento de Benidorm, que los reentregaría a Naviera Ibérica, S.A. el 4 de diciembre. Se estima que el volumen de agua transportado por dichos barcos en dos meses, octubre y noviembre, totalizó $500.000-550.000 \mathrm{~m}^{3}$. El coste total de la operación ascendió a 170.000.000 pesetas, en torno a 6.000.000 de euros actuales, de los que 50.000.000 correspondieron a los fletes. En suma, el coste de metro cúbico de agua trasvasada subió a 309-340 ptas, cifra que multiplicaba por 20-23 el precio (15 ptas $\left./ \mathrm{m}^{3}\right)$ facturado por Aguas Municipalizadas de Alicante; dicho valor, desorbitado en circunstancias normales, no lo fue dada la particularidad del problema, ya que la arriesgada y bien resuelta operación de emergencia no sólo conjuró gravísimos riesgos higiénicos y sanitarios, sino que, además, permitió, en última instancia, salvar la imagen, tan dañada y en peligro letal, de Benidorm. Además, la angustiosa experiencia amparó y acicateó actuaciones que han permitido enfrentar, con indudable éxito, el desafío natural de la escasez e irregularidad de disponibilidades hídricas en la comarca de la Marina Baja.

\section{Abastecimiento urbano y uso agrícola: aguas blancas y residuales regeneradas}

El decidido propósito de incrementar los recursos hídricos, con criterio de sostenibilidad, y de optimizar su gestión, para garantía del suministro a poblaciones y racionalización del aprovechamiento agrícola, armonizando ambos, pasaba por una serie de decisiones interrelacionadas, novedosas y de indudable calado. Primordialmente, mejora de los sistemas de captación, diversificación de los mismos, añadiendo, a la aguas epigeas y subterráneas de las cuencas del Algar-Guadalest y Amadorio, la reutilización de depuradas y, frente a episodios intensos y duraderos de sequía, el auxilio de los caudales foráneos; reforzado dicho aumento de disponibilidades por una regulación amplia tanto de epigeas y subterráneas, mediante los oportunos bombeos y conexión de las indicadas cuencas fluviales, como de residuales regeneradas, a través de infraestructuras hidráulicas muy flexibles, capaces de permitir el acomodo a circunstancias pluviométricas, más que dispares, del todo opuestas. Este conjunto de actuaciones debía, además, hacer posible, el intercambio de aguas blancas por regeneradas, mediante compensaciones e incentivos, para destinar, preferentemente, las primeras a abastecimiento y las segundas, en exclusiva, a riego.

Es de notar que, por el extraordinario desarrollo de la actividad turística y, con ella, de la construcción, en la distribución del Consorcio el consumo urbano excede en mucho al agrícola, con porcentajes respectivos en el último lustro (2005-2009) de 76,46 y 23,54. La 
demanda urbana fue atendida por completo con agua blanca, y ascendió durante ese período a $105.888 .481 \mathrm{~m}^{3}$; a diferencia, en los $32.602 .537 \mathrm{~m}^{2}$ para riego, las aguas regeneradas $\left(16.999 .561 \mathrm{~m}^{3}\right)$, con el $52,14 \%$, rebasaron ligeramente a las blancas $\left(15.602 .976 \mathrm{~m}^{3}\right)$. La distribución anual fue la siguiente:

Demandas de agua municipales

\begin{tabular}{ccc} 
Abastecimiento $\left(\mathrm{m}^{3}\right)$ & \multicolumn{2}{c}{ Riego $\left(\mathrm{m}^{3}\right)$} \\
\cline { 3 - 3 } Blancas & Blancas & Depuradas \\
22.079 .334 & 4.546 .491 & 3.387 .877 \\
21.874 .033 & 3.907 .976 & 4.082 .164 \\
21.162 .637 & 2.421 .179 & 3.932 .444 \\
20.999 .108 & 2.104 .587 & 3.535 .836 \\
19.773 .369 & 2.622 .743 & 2.061 .240
\end{tabular}

En 2008 la estructura de la demanda de agua atendida por el Consorcio fue esta:

\begin{tabular}{lrrr}
\multicolumn{1}{c}{ Municipios } & Habitantes & Abastecimiento $\left(\mathrm{m}^{3}\right)$ & Riego $\left(\mathrm{m}^{3}\right)$ \\
Benidorm & 69.085 & 12.855 .994 & 3.524 .965 \\
Villajoyosa & 30.550 & 2.529 .730 & 2.183 .120 \\
Altea & 22.648 & 1.140 .411 & 1.221 .623 \\
Alfaz del Pí & 19.913 & 2.532 .326 & 2.349 .977 \\
La Nucía & 15.519 & 1.595 .146 & 152.936 \\
Finestrat & 4.945 & 719.445 & 0 \\
Polop & 3.869 & 546.014 & 1.120 .604 \\
Otros & ----- & 1.428 .328 & 0 \\
& & & $16.860 .495^{*}$
\end{tabular}

A tenor de esos datos, la población servida sumaba 166.529 personas, cifra que en estío se cuadriplicaba, hasta un máximo de 680.000 , con un consumo para dicho período de 51.000 $\mathrm{m}^{3}$ diarios. En cuanto a la distribución de la demanda, el abastecimiento a poblaciones, con casi $60 \%(59,86)$, excedió ampliamente al uso agrícola.

Los contrastes anuales entre las aportaciones de agua blancas y depuradas, para el intervalo 1996-2009, en ocasiones muy marcados, dependen ampliamente de la irregularidad pluviométrica. En años lluviosos, los volúmenes distribuidos por el Consorcio, para abastecimiento y riego, provienen, esencialmente, de ríos y manantiales. Ejemplos prototípicos constituyen, al respecto, los años 2004 y 2008, con caídas muy pronunciadas en el empleo de aguas depuradas, con tan sólo 9,49 y 13,27 \% del total; y aún menos $(8,43 \%)$ en 2009 , año que, además de lluvioso, contó con las reservas acumuladas en el precedente. Baste recordar algunos datos significativos: en 2004, las Fuentes del Algar proporcionaron el $23 \%$ del volumen servido, al tiempo que acrecentaban las reservas

* $\quad$ Los totales incluyen 1.799.782 y 6.307.270 $\mathrm{m}^{3}$ del municipio de Callosa d'En Sarriá, que si bien puede abastecerse desde el embalse de Guadalest, lo hace directamente de los acuíferos del Algar y Polop; y en 2008, por completo, de este último. 
de los embalses de Guadalest y Amadorio. Otro tanto aconteció en 2008: los caudales para abastecimiento y riegos fueron procurados, casi en exclusiva, por ríos y fuentes, sin apenas bombeo de subterráneas; incluso, la segunda quincena de septiembre y comienzos de octubre, ante la previsión de fuertes lluvias, para mantener el resguardo de seguridad en la presa, resultó preciso abrir el desagüe de fondo del embalse de Amadorio; práctica ésta ineludible bajo ese condicionamiento, pero nada grata a los usuarios de abastecimientos y, sobre todo, riego.

Situación radicalmente distinta a la anterior fue la del trienio 1999-2001, período seco, con fuerte protagonismo de las aguas depuradas que contribuyeron con 24,70\%, 21,62 y 23,29 a la demanda al Consorcio. Fue preciso asimismo el envío, a través del Acueducto Tajo-Segura, Postrasve y Conducción Fenollar-Rabasa-Amadorio, de caudales del Júcar, desde el hiperembalse de Alarcón, para garantizar el abastecimiento de los núcleos urbanos. En suma, hoy la garantía de suministro del Consorcio a los municipios de la Marina Baja radica en tres sistemas fundamentales (Algar-Guadalest, Amadorio-Sella y Reutilización de Aguas Depuradas), a los que se añade, en emergencias como la indicada, la Conducción Fenollar-Rabasa-Amadorio.

\section{Aguas epigeas y subterráneas de la cuenca del Algar-Guadalest}

De la unión de pequeños regatos en la sierra del Carrascal nace el río Algar. El curso sigue rumbo norte-sur al pie de las estribaciones de la sierra de Bernia, y, en el corto trayecto de $25 \mathrm{~km}$ hasta su desembocadura en las inmediaciones de Altea, recibe como mayores tributarios la rambla de Bolulla, que drena el valle de Tárbena y, sobre todo, al Guadalest; este río, regulado por el embalse $\left(12,5 \mathrm{hm}^{3}\right)$ de su nombre y más caudaloso que el propio Algar en la confluencia, nace en las proximidades del puerto de Confrides, llega a Beniardá y recorre el valle de Guadalest fuertemente encajado; a su paso por los términos de Callosa d'En Sarriá, Polop y La Nucía recoge los excedentes de diversos manantiales y los aportes del río de Xirles. La cuenca avenada por el Algar y sus afluentes, limitada por la sierras de Bernia y Ferrer al este, las de Carrascal, Castell y Serrella al norte, el puerto de Confrides y Aitana al oeste, y, por último, Coll del Llamp y Foies Blanques hasta Altea, totaliza $228 \mathrm{~km}^{2}$.

Los contrastes pluviométricos entre las cuencas del Algar-Guadalest y Amadorio resultan muy notorios: con datos de la serie 1961-90, la pluviometría anual media de la primera asciende a $690 \mathrm{~mm}$, mientras la segunda (296) no llega a 300. Ambos regímenes son pluviales, pero con la diferencia esencial que el del Algar corresponde a un clima templado subtropical de verano seco y filiación mediterránea, mientras el segundo, adscrita mayoritariamente su cuenca a la región geográfica del Sureste Ibérico, es semiárido subtropical de verano seco y raigambre mediterránea. Los módulos reflejan asimismo esta diversidad, por más que los datos foronómicos sean históricos; así, en el intervalo de 1907-8 a 1933-34, el Guadalest, en Callosa, con superficie vertiente de $121 \mathrm{~km}^{2}$, registró módulo de $0,787 \mathrm{~m} 3 / \mathrm{s}$ y caudal específico de $6,50 \mathrm{l} / \mathrm{s} / \mathrm{km}^{2}$; cifras que, en el intervalo de 1908-9 a 1950-51, para el Algar, con $73 \mathrm{~km}^{2}$ en Algar, subían a 0,909 y 12,45. Por supuesto, ambos valores eran muy inferiores para el Amadorio, que, en Orcheta $\left(103 \mathrm{~km}^{2}\right)$, quedaba en $0,102 \mathrm{~m}^{3} / \mathrm{s}$ y tan sólo $0,99 \mathrm{l} / \mathrm{s} / \mathrm{km}^{2}$, condignos a su condición de modesto río-rambla.

Es de resaltar la elevada caudalosidad relativa del Algar $\left(12,45 \mathrm{l} / \mathrm{s} / \mathrm{km}^{2}\right)$. Como se ha indicado, se trata de una reducida superficie vertiente $\left(73 \mathrm{~km}^{2}\right)$, que recoge parte de los derrames de las sierras de Carrascal y Bernia, que sobrepasan $1.000 \mathrm{~m}$; y el carácter anfractuoso del relieve facilita la escorrentía y dificulta el riego del terrazgo. Con todo, el factor primordial parece ser la reaparición de caudales infiltrados en espacios limítrofes; se trata, 
por otra parte, de fenómeno conocido desde antiguo: un estudio para aprovechamiento de las aguas del Algar encontró que la precipitación $(654 \mathrm{~mm})$ medida, el año 1864, en Callosa d'En Sarriá debía proporcionar un débito teórico de $0,994 \mathrm{~m} 3 / \mathrm{s}$, mientras el aforado subió a 2,420 m³/s; en idéntico sentido, se aducía el hecho de que la Font de la Figuera, tributaria del Algar y seca varios años, había vuleto a manar cinco días después que descargarse una fuerte tormenta sobre Castell de Castells, término adscrito a la cuenca del Jalón.

En cualquiera de los aforos, la irregularidad interanual, que traduce la de las precipitaciones, es muy elevada para Algar y Guadalest, que han llegado a quedar secos. Baste recordar que, en la segunda mitad del siglo XX, al menos en un par de ocasiones, en 1969 y 1978, dejaron de manar las Fuentes del Algar, ocasionando serias dificultades en el abastecimiento de agua a Benidorm.

Como rasgos sobresalientes, en régimen natural, la curva anual de coeficientes mostraba los siguientes para Algar (Algar) y Guadalest (Callosa): máximo principal de primavera en torno a 1,5 en marzo o abril, mientras mayo no llega a 1 y la actividad tormentosa en junio no es suficiente a establecer pico alguno; aguas muy bajas de estío y mínimo generalizado de agosto, con menos de 0,5 en el aforo más favorecido; pico otoñal próximo al máximo de primavera, con ascenso rápido de las aguas pasado octubre; y, por último, mínimo secundario, poco acentuado, de enero, siempre superior a la unidad. La única excepción es la del Guadalest, con baja secundaria en marzo. Este desplazamiento, al igual que el del pico otoñal y el estiaje relativamente moderado de agosto obedecen a la importancia, ya indicada, de la alimentación subterránea.

El régimen natural de Guadalest y Algar ha sido profundamente alterado por el embalse de Guadalest y otras actuaciones humanas. Las curvas de coeficientes han quedado invertidas, situándose, a la salida de aquéllos, el período de aguas altas en verano, cuando mayor es la demanda. Por lo que hace a disponibilidad para abastecimiento urbano, el problema esencial es la irregularidad interanual de las precipitaciones, lo que ha exigido potenciar otras fuentes de suministro.

En el verano de 1978, agotadas las reservas embalsadas en Guadalest y secas las Fuentes del Algar, se hizo muy patente la urgente necesidad de potenciar el empleo de recursos subterráneos; $y$, junto a ello, la innegable conveniencia de diversificar las fuentes de captación, incluyendo la reutilización de aguas depuradas y, para fortalecer la garantía de suministro, hasta casi la seguridad, la transferencia de recursos foráneos. Con el precedente de las norias de tracción animal, el aprovechamiento de freáticos someros poseía gran tradición en la Marina Baja, continuada por la instalación de motobombas, que, desde mediados del siglo XX, con la difusión de las de eje vertical y electrobombas sumergidas de gran potencia, contaba con nuevas perspectivas y posibilidades.

En el sector comarcano del Prebético de Alicante y espacios aledaños los mejores acuíferos corresponden a las calizas fisuradas y carstificadas del Cretácico superior (TuronienseMaastrichtiense) y, en segundo lugar, a formaciones eocenas y oligocenas. Sondeos y pozos se localizan, primordialmente, en la cuenca del Algar-Guadalest, sobre los acuíferos de Beniardá-Polop, Carrascal-Bernia y Serrella-Aixorta, todos ellos con manantiales abundantes y de excelente calidad. El de Beniardá-Polop, con extensión de $165 \mathrm{~km}^{2}$, recarga anual de $15 \mathrm{hm}^{3}$ y extracción de 13, cuenta entre sus puntos de descarga las Fuentes de Chirles, Garrofer y Corelles, que nutren la conocida Fuente de los Chorros, en Polop, con 221 caños. Las Fuentes del Algar, con su espectacular cascada, y la del Amor radican en el acuífero de Carrascal-Bernia, de $90 \mathrm{Km}^{2}$, con bombeo de $11 \mathrm{hm}^{3} /$ año y entrada de 13 . Más reducido, tan sólo $40 \mathrm{~km}^{2}$, de $2,5 \mathrm{hm}^{3} /$ año de ingreso y 2,2 de salida, es el acuífero de Serrella-Aixorta. En general, se trata de aguas bicarbonatadas cálcico-magnésicas de baja mineralización, muy indicadas para consumo humano. 
Por supuesto, si bastan las aportaciones fluviales, reguladas por los embalses, y las de las fuentes, los pozos sólo funcionan a efectos de mantenimiento; así, por ejemplo, el año 2008, la situación de bonanza hidrológica, -las Fuentes del Algar y del acuífero de Beniardá proporcionaron el 37,46 \% de los recurso distribuidos por el Consorcio-, supuso que éstos proviniesen «fundamentalmente de aportaciones naturales de ríos, emanaciones naturales de fuentes, pudiendo prescindir prácticamente de las aportaciones subterráneas de los pozos de bombeo» (Consorcio de Aguas de la Marina Baja:Informe anual'08, pág. 25).

En Polop se practicaron los primeros sondeos para abastecer los municipios costeros. Mediados los sesenta, poseía capital interés la captación conocida por Pozo Rabasa, que rendía casi 50 1/s $(49,91) \mathrm{m}$, contaba con un depósito regulador $\left(1.500 \mathrm{~m}^{3}\right)$ y, luego de atravesar el término de La Nucía mediante una conducción de $250 \mathrm{~mm}$ de diámetro, proporcionaba la mayor aportación a los Depósitos Municipales de Benidorm. En la actualidad, son tres los pozos en explotación (Polop I, Polop II y San Vicente), distantes entre ellos 1,5 km, a profundidades entre 150 y $300 \mathrm{~m}$, capaces de bombear, en total, 200 1/s. A la cola del embalse de Guadalest se sitúa el campo de pozos de Beniardá; los sondeos realizados entre 1979 y 1995, son diez, a 300-400 m de profundidad, y operativos se encuentran seis, con capacidad punta de 500 l/s. Superior $(600$ l/s) es el rendimiento de las tres captaciones de Algar, cuyos titulares son Ayuntamiento y Comunidad de Regantes de Callosa d'En Sarriá, que comparten dichos recursos con el Consorcio de Aguas de la Marina Baja; éste proporciona el suministro eléctrico desde la Subestación de Algar. Por otra parte, es obligado recordar que las aportaciones al embalse de Guadalest, concluido en 1964, con superficie vertiente de $75 \mathrm{~km}^{2}$ y vaso de $12,5 \mathrm{hm}^{3}$, radicado en tierras de Guadalest, Benimantell y Beniardà, proceden, fundamentalmente, de la regulación del acuífero de Carrasca-Bernia a través de la impulsión existente en el río Algar, de las fuentes y extracciones del acuífero de Beniardá y de las propias aportaciones del río Guadalest. Así pues, la regulación del embalse desborda ampliamente la del río e incluye la de acuíferos, en especial con el bombeo de caudales de las Fuentes del Algar.

\section{Abundancia escasa e irregular del río-rambla Amadorio}

La cuenca de recepción del barranco de Monferri, tramo inicial del Río de la Vila o Amadorio, a $1.000 \mathrm{~m}$ de altitud, reúne, como más importantes, los torrentes de la Canaleta, Puerto de Benifallim y Taular. La pequeña corriente así formada, luego de un corto tramo oeste-este, se dirige hacia el sureste en busca del Mediterráneo. Hasta el pantano de Relleu, enteramente enrunado, recibe como afluentes de mayor entidad los barrancos de Regall y Escuders, por la izquierda; y, por la otra margen, los de Surca, Bortolons y Cova. Aguas abajo, al suroeste de Orcheta, en el embalse de Amadorio $\left(15,3 \mathrm{hm}^{3}\right)$, se le une el Sella, el más importante de sus tributarios. Este, presenta disposición palmeada en cabecera, con la reunión de los barrancos del Arco y Tagarina, que recogen derrames de Aitana; después, se incorpora el arroyo de Xarques, procedente de las estribaciones del Puig Campana. Finalmente, el Amadorio, luego de recibir las aguas eventuales de una serie de barrancos, atraviesa Villajoyosa muy encajado, para terminar al sur del núcleo. Sus $207 \mathrm{~km}^{2}$ de cuenca quedan encuadrados, al este, por las sierras de Orcheta y Realet y la Peña del Contador; al norte por la sierra de Aitana y sus estribaciones hasta el puerto de Benifallim; y, al oeste, por los contrafuertes de las sierras de Grana, Cabezo de Oro y Busot, con sus ramificaciones hasta el litoral.

Como se ha hecho notar, los rasgos definitorios del Amadorio difieren sustancialmente de los del Algar. Este es un río autóctono de régimen pluvial subtropical de verano seco y filiación mediterránea; el segundo, un río-rambla de régimen semiárido subtropical de 
verano seco y raigambre mediterránea. Los datos, ya indicados, muestran, con claridad, un curso caracterizado por: escasa abundancia, débil coeficiente de escorrentía, módulo específico ínfimo, fortísima irregularidad interanual, máximos equinocciales, profundo mínimo estival y violentas crecidas-relámpago. Estas variaciones estacionales, en régimen natural, muy desvirtuado por la acción humana, son las de un río-rambla, similares a las de Monnegre y Vinalopó, y resultan más pronunciadas que las del Algar. El máximo principal es de otoño, y ofrece proporción próxima a la de mínimo estival; por su parte, las aguas primaverales varían mucho de uno años a otros, y la ubicación del pico secundario, sensiblemente inferior al de otoño, depende de la cronología de una o dos riadas fuertes. Es de recordar que, como en los restantes ríos-ramblas alicantinos y murcianos, en el Amadorio se produjo también la disociación entre las propiedades de agua y tierra, ya que, en expresión de Brunhes, la primera es, en la región geográfica del Sureste Ibérico, el «bien por excelencia», y conseguirla es un desafío vital que llega hasta hoy, como evidencian las actuaciones pasadas y actuales en el sistema Amadorio-Sella.

Baste recordar que el embalse de Amadorio, a caballo de Villajoyosa y Orcheta, con superficie vertiente de $240 \mathrm{~km}^{2}$ y capacidad de $15,8 \mathrm{hm}^{3}$, que sucedió en 1957 al dieciochesco y cegado pantano de Relleu, recibe caudales de muy variado origen, ya que a los de la red fluvial del Amadorio-Sella, incluidas las salidas naturales del acuífero Aitana Sur, se suman, a través del Sistema Mandem-Canal Bajo del Algar-Torres, los excedentes de la cuenca Algar-Guadalest y, eventualmente, los de la conducción Fenolla-Rabasa-Amadorio, con agua del Júcar. En suma, los recursos regulados por el embalse proceden de las escorrentías epigeas de las cuencas del Amadorio y Sella y de la Font del Arc, salida natural del acuífero de Aitana Sur. Sin embargo, la mayor aportación procede de los sobrantes y escorrentías de los ríos Algar y Guadalest, transportados por el Canal Bajo del Algar hasta el azud del río Torres, donde, junto a los escasos caudales de este curso, son impulsados, desde la Estación de Bombeo de Mandem, hasta el embalse de Amadorio. Un ejemplo prototípico éste del grado de integración y flexibilidad que caracterican la gestión de los recursos hídricos por el Consorcio de Aguas de la Marina Baja.

\section{Conducciones generales de aguas blancas}

La conexión de los sistemas Algar-Guadalest y Amadorio en la gestión integral de recursos hídricos que realiza el Consorcio se efectúa mediante cuatro conducciones generales. Singular importancia reviste la denominada Conducción General de Guadalest, si bien su origen es doble: Estación de Bombeo del Algar, en término de Callosa d'En Sarriá, y Embalse de Guadalest; de la primera arranca una conducción de impulsión en chapa de acero, $900 \mathrm{~mm}$ de diámetro y 3,014 km hasta su confluencia en Callosa d'En Sarriá con el otro ramal, que parte del citado pantano, también en chapa de acero, $800 \mathrm{~mm}$ de anchura y $6,96 \mathrm{~km}$ de recorrido. Este segundo es de funcionamiento reversible: si el caudal a distribuir es inferior al bombeado en aquella Estación, el resto pasa al Embalse de Guadalest, que actúa entonces como regulador del Algar; en caso opuesto, el Embalse suplementa la diferencia. Desde el entronque en Callosa, la conducción de fibrocemento atraviesa los términos de Callosa, Polop y La Nucía en dirección Benidorm, con longitud de 12,10 km y diámtro de 700-500. Conducción y derivaciones totalizan $55,5 \mathrm{~km}$, con diámetros que varían entre 900 y $150 \mathrm{~mm}$; tanto en aquélla como algunas de éstas hay intercalados obturadores, elementos hidromecánicos cuya finalidad es disipar la carga disponible y reducir timbrajes, al existir $300 \mathrm{~m}$ de desnivel entre el Embalse de Guadalest y las derivaciones finales, prácticamente a nivel de mar. En la actualidad se lleva a cabo un desdoblamiento de la referida conducción general en fundición, concluido hasta el obturador $\mathrm{n}^{\circ} 4$, ya en 
término de Benidorm; dicha mejora posibilita gran variedad de maniobras y procura mucha flexibilidad, dada la superioridad mecánica de la fundición sobre el fibrocemento que, mediante by pass en obturadores, permite elevadas presiones en distribución, con notable incremento de la capacidad de transporte.

Desde el Embalse de Amadorio parte otra conducción general, por gravedad, hasta Benidorm, a lo largo de 15,3 km y diámetros de 700-600 mm. Alimenta los Depósitos Municipales de Villajoyosa, su potabilizadora y, mediante un bombeo intermedio, abastece Finestrat y, provista de los obturadores necesarios, las Estaciones de Aguas Potables (ETAP) de Benidorm. Al igual que las anterioes, excelentes muestras de la amplia interconexión de los sistemas de aguas blancas son las conducciones generales de la Impulsión de Torres y Aitana Sur. La primera, tendida entre la Estación de Bombeo del Río Torres y el Embalse de Amadorio, permite conducir a éste, en su caso, los excedentes de la cuenca del AlgarGuadalest, para paliar el déficit crónico en la del río-rambla Amadorio. Este cometido asumirá también la conducción general de Aitana-Sur, que discurre al sur de esta sierra, por los términos de Benimantell y Sella. Finalizada la primera fase entre el campo de pozos de Aitana Sur y Sella, la segunda llegará también al Embalse de Amadorio, con recorrido total de $13,7 \mathrm{~km}$.

\section{Regeneración y reutilización de residuales}

Dos referencias esenciales, escasez e irregularidad de disponibilidades hídricas y, junto a ello, fuerte primacía del abastecimiento en la demanda de agua, hacían ineludible, en una planificación hidrológica adecuada, atribuir lugar significativo a la regeneración y reutilización de residuales. Además, como se ha subrayado, en la gestión integral del recurso, logro singular y muy notorio del Consorcio es el intercambio y sustitución de aguas blancas por recicladas, para destinarlas a suministro urbano y riego respectivamente. En el último septenio, los caudales reutilizados, con media anual de $5.436 .845 \mathrm{~m}^{3}$, han supuesto la cuarta parte de las servidas por el Consorcio, con mínimo de $17,70 \%$ en 2004 y máximo de 3,50 para 2007; ampliado el intervalo a 1996-2009, el porcentaje $(17,38 \%)$ es inferior, por pluviometría más favorable, y los extremos corresponden a $2009(8,43)$, año hidrológico muy abundante, en cifras absolutas $\left(7.602 .971 \mathrm{~m}^{3}\right)$, pero no relativas $(24,70)$, y 1999, éste seco, con déficit enjugado por transferencia del Júcar a través de la conducción FenollarRabasa-Amadorio. Salvo Callosa d'En Sarriá y Polop, términos que reúnen el $60 \%$ del regadío comarcal, bien dotados en aguas subterráneas, que no utilizan regeneradas, los restantes municipios comparten ambos recursos.

La considerable reutilización de aguas depuradas ha requerido amplias infraestructuras específicas. Por volumen y calidad del proceso, el centro neurálgico del sistema es la Estación de Depuración de Aguas Residuales (EDAR) de Benidorm, ubicada, a 141 metros de altitud, en Sierra Helada, posición eminente que permite, a un tiempo, librar de efluvios nada gratos a la ciudad y enviar, por gravedad, las aguas regeneradas a los puntos de destino. Inaugurada en 1982, esta instalación ha sido mejorada, en 2007, con otra de tratamiento terciario, dotada de fases diferenciadas de ultrafiltración y ósmosis inversa, a la que se ha añadido una desaladora; el conjunto, con capacidad de $25.000 \mathrm{~m}^{3}$ diarios, proporciona agua regenerada de excelente calidad. También los fangos conocen un completo proceso de digestión, que los habilita para uso agrícola; y se obtiene asimismo, como subproducto, biogás de elevado contenido en metano, empleado en parte como combustible para las calderas de los digestores y el resto en cogeneración de energía eléctrica para la planta; por último, el gas sobrante arde en una antorcha. La EDAR de Benidorm trata las residuales de esta ciudad y Alfaz del Pí, mientras Villajoyosa y Altea cuentan con sus respectivas Estaciones. 
Las infraestructuras de reutilización incluyen también cuatro estaciones de impulsión, grandes balsas reguladoras y tres conducciones generales. Las estaciones impulsoras de aguas regeneradas se denominan «Villajoyosa-1», «Villajoyosa-2», «Villajoyosa-3» y «Altea-1». La primera impulsa a cabeza de riego efluentes de las EDAR de Benidorm y Villajoyosa, y es la de mayor capacidad, con 3 bombas sumergibles en el pozo de bombeo, capaces de elevar, conjuntamente, $350 \mathrm{l} / \mathrm{s}$ a $35 \mathrm{~m}$; hay una cuarta bomba, ésta en cámara seca, que puede elevar a $8 \mathrm{~m} 200 \mathrm{l} / \mathrm{s}$ del embalse $\left(75.000 \mathrm{~m}^{3}\right)$ que almacena depuradas de las EDAR de Benidorm y Villajoyosa. Por su parte, la impulsión «Villajoyosa-2», $1 \mathrm{~km}$ aguas debajo de la presa de Amadorio, eleva el referido Embalse Regulador de Riego, aguas de la EDAR de Villajoyosa y filtraciones de aquélla. Por último, la Estación «Altea-1» movilica caudales de la EDAR de esta ciudad y subálveas del Algar en su tramo final; vertidas a dicho río, proporcionan un módulo prácticamente constante para riego.

Los reservorios de más entidad para almacenamiento y regulación de aguas depuradas se sitúan junto a las EDAR de Benidorm y Villajoyosa: una balsa de $5.000 \mathrm{~m}^{3}$ basta a la primera, ya que la de Villajoyosa $\left(75.000 \mathrm{~m}^{3}\right)$ regula aportes de ambas EDAR. Con todo, la mayor obra de regulación es la llamada Balsa Alfondons $\left(310.000 \mathrm{~m}^{3}\right)$, conectada a la EDAR de Villajoyosa.

Además, el sistema de reutilización de residuales regeneradas dispone de tres conducciones generales. La de mayor capacidad corresponde a la EDAR de Benidorm, que permite, por sustitución, liberar aguas blancas del Canal Bajo del Algar; la conducción recorre 4,040 km, con capacidad de 600 1/s hasta Alfaz del Pí, donde se bifurca en los canales de Altea y Villajoyosa. De esta conducción, aunque no es sino prolongación suya, se distingue la que lleva agua de las estaciones de Benidorm y Villajoyosa; consta de tres tramos: el primero vierte en el Embalse Regulador de Riego aguas de la EDAR de Villajoyosa y filtraciones del pantano de Amadorio; el segundo conecta el referido Embalse Regulador con la Impulsión «Villajoyosa-1», y es reversible, de modo que, si el efluente de la EDAR excede las necesidades de riego, el remanente acaba en aquél, y, si ocurre lo contrario, se complemente el caudal a expensas del citado Embalse Regulador; el tercero y último tramo discurre desde la EDAR «Villajoyosa-1», hasta el pie de la presa de Amadorio, de donde arranca la red de riego. La cuarta es la conducción para reutilizar aguas de la EDAR de Altea y subálveas que afloran cerca de la desembocadura del Algar, para entregarlas en el área de regadío más extensa de Altea.

\section{Transferencias de caudales foráneos: pasado y presente}

Con el recuerdo perenne de la durísima experiencia de 1978 y la prudente decisión de prevenir, al máximo, las consecuencias de prolongados e intensos episodios de sequía, se planteó la necesidad de contar con la cobertura protectora que procuran los trasvases de recursos lejanos. Se pretendió, primero, la conexión con el Júcar, y después, ya en el marco del Plan Hidrológico Nacional de 2001, la participación en el trasvase del Ebro.

El Proyecto de Directrices del Plan Hidrológico de la Cuenca del Júcar, hecho público en 1992, incluía, entre las grandes conducciones con el horizonte del año 2002, el Canal Júcar-Marinas-Vinalopó, haciendo constar a pie de página que su finalidad era la transferencia de recursos para reducir sobreexplotación, con inclusión de abastecimientos (pág. 174). Se trataría, según el expresado documento, de «una transferencia interna de recursos, a corto plazo, de $100 \mathrm{hm}^{3}$ para atender los déficit de abastecimiento urbano y la sobreexplotación de acuíferos en las comarcas del Alacantí, Marina Baja y Vinalopó» (págs. 115-116). Con fecha 26 de octubre de ese mismo año, el Gobierno Valenciano, en manos del Partido Socialista Obrero Español (PSOE), formulaba, entre las alegacio- 
nes generales al referido Proyecto de Directrices, la siguiente: «Si bien compartimos la postura del proyecto a favor de una transferencia de $100 \mathrm{hm}^{3} /$ año desde el Júcar al Vinalopó-Alacantí y a la Marina-Baja, entendemos que esa transferencia es un mínimo a corto plazo, por lo que el proyecto deberá contemplar que esa transferencia será completada en un momento posterior por el aporte de los recursos adicionales que resulten precisos para el restablecimiento del equilibrio hídrico de estas zonas a medio y largo plazo» (Alegaciones definitivas de la Generalitat Valenciana al Proyecto de Directrices del Plan Hidrológico del Júcar, 1992, pág. 7); sobre este aspecto insistía una propuesta de modificación que subrayaba «la necesidad de aportes suplementarios a los $100 \mathrm{hm}^{3} /$ año previstos en el Proyecto para la Marina Baja-Vinalopó-Alacantí» (pág. 26). Unos meses después, el Anteproyecto del Plan Hidrológico Nacional remitido al Consejo Nacional del Agua, en 25 de abril de 1993, relacionaba el Canal Júcar-Vinalopó entre las actuaciones previstas en la Cuenca del Júcar.

Como se observa, de un documento a otro, y a veces en el mismo, las enumeraciones, de las comarcas beneficiarias del trasvase no guardaban idéntico orden, como resultaría lógico, y casi automático, en un canal planteado sin reservas. El dato dista de ser mera curiosidad o puro entretenimiento por cuanto, muy pronto, el trazado costero fue desechado; concebido para evitar conflictos concesionales y, en íntima relación, el rechazo por los regantes del Júcar y la propia ciudad de Valencia de cualquier toma aguas arriba de Antella, se reveló inviable, no sólo por la cuantiosa inversión requerida y su costosa explotación, sino sobre todo, por la escasa calidad, completamente inadmisible para abastecimientos, de un recurso de segundo o tercer ciclo deteriorado por intensos procesos de contaminación.

El 11 de mayo de 1995, aún en el marco de una dura y prolongada sequía iniciada cuatro años antes, el director general de Obras Hidráulicas declaraba que el proyecto de trasvase Júcar-Vinalopó ya se hallaba redactado y que «ahora se va a proceder a la supervisión final y a la aprobación de ese proyecto para sacarlo a información pública». La nueva versión de la transferencia aprovechaba, desde Alarcón, las infraestructuras del trasvase y postrasvase Tajo-Segura, idea anticipada un lustro atrás por el malogrado director técnico de la Confederación Hidrográfica del Segura Alfonso Botía. Ya en la cuenca del Segura, las aguas del Júcar llegarían a la presa de Ojós y luego, por el canal de la margen izquierda, alcanzarían, en la cota 125 , el pantano de Crevillente, y desde allí serían elevadas a un reservorio que se construiría, aproximadamente a 400 metros de altitud, aprovechando una vaguada entre Aspe y Hondón de las Nieves, con un vaso de $11 \mathrm{hm}^{3}$. De este embalse partiría un canal que, tras distribuir las dotaciones asignadas en el Medio Vinalopó, seguiría por Agost para conducir a la Marina Baja, a través del Amadorio, un volumen de $15 \mathrm{hm}^{3}$ anuales con destino a abastecimiento urbano. A la postre, pesaron mucho más los inconvenientes que las ventajas, y este proyecto, al igual que el Anteproyecto de Plan Hidrológico Nacional de 1993, quedó descartado.

Sin embargo, no cabe olvidar que el auxilio del Júcar, en el episodio de sequía de los años noventa, llegaría a la Marina Baja por medio del Acueducto Tajo-Segura, a partir de Alarcón, y de la infraestructura de la Mancomunidad de los Canales del Taibilla. Avivado el preocupante recuerdo del verano-otoño de 1978 por la intensa y prolongada sequía de 1992-95, solicitada y obtenida la pertinente licencia, Aguas del Júcar, S.A. realizó, a petición del Consorcio, la conexión entre la red en alta de la Mancomunidad de los Canales del Taibilla y el embalse de Amadorio, para garantizar el abastecimiento de los municipios consorciados con recursos del Júcar. Dicho enlace se inicia en la Cañada de Fenollar (Alicante), a partir de un depósito de $7.500 \mathrm{~m}^{3}$, con un primer tramo de impulsión de $800 \mathrm{~mm}$ de diámetro y 4,8 km hasta el depósito regulador de Rabasa, en San Vicente del Raspeig; y desde aquí, por gravedad, a través de los términos de San Vicente, Mutxamel, San Juan, 
El Campello y Villajoyosa, con recorrido de $35 \mathrm{~km}$ y diámetros de 800-600 mm, conecta con la Conducción General del Amadorio. La nueva infraestructura permitió sortear, sin mayor problema, un nuevo episodio de sequía entre 1999 y 2002, con envío de 6,3, 7,9, 10,9 y $0,2 \mathrm{hm}^{3}$ en los años respectivos. Se trataba de una mera solución de emergencia a la espera de la transferencia Júcar-Vinalopó-Marina Baja, incluida en el Plan Hidrológico de la Cuenca del Júcar, aprobado por Real Decreto de 24 de julio de 1998, y en la Ley 10/2001, de 5 de julio, del Plan Hidrológico Nacional.

Sin embargo, la alternancia política en el gobierno de la nación, en junio de 2004, conllevó, de manera inmediata, la derogación parcial de la Ley del Plan Hidrológico Nacional de 5 de julio de 2001, con supresión de la transferencia del Ebro; asimismo la conexión Júcar-Vinalopó, con su primer y costoso tramo muy avanzado, sufrió una profunda desnaturalización, al cambiarse la toma de Cortes por el Azud de la Maquesa, comienzo del estuario, en término de Cullera, es decir, aguas blancas por retornos que, como se ha dicho, dada su mada calidad, habían sido descartados en los ochenta por la misma opción política que ahora los imponía. No era ésta la transferencia convenida con la Junta Central de Usuarios del Vinalopó, Alacantí y Consorcio de Aguas de la Marina Baja por el Ministerio de Medio Ambiente, que ahora rompía el acuerdo de forma expeditiva y unilateral. Hoy, sólo la inclusión de una segunda toma próxima a Antella y aguas abajo del Azud, indispensable para abastecimientos, haría viable la transferencia; y atenuaría el rechazo generalizado de sus potenciales y defraudados usuarios.

\section{Algunas conclusiones}

Ubicada en la región geográfica del Sureste Ibérico, cuyo rasgo definitorio esencial es la aridez, históricamente la villa de Benidorm ha padecido un abastecimiento de agua insuficiente e inseguro, precariedad que adquirió nueva y extraordinaria dimensión con el vertiginoso desarrollo urbano suscitado por el estallido del fenómeno turístico, actividad económica de singular trascedencia para la balanza de pagos y economía españolas, que ha tenido y tiene en Benidorm uno de sus núcleos más potentes. Desde el primer momento, fue evidente que la limitación y amenaza principal del espectacular despegue era la escasez e irregularidad de disponibilidades hídricas, endurecidas a penuria extrema en las prolongadas e intensas sequías.

En el difundido informe Benidorm, ciudad nueva, coordinado por Mario Gaviria y publicado en 1977, se hacía constar que «la escasez de agua en Benidorm y la gestión de recursos hidráulicos ha sido una obsesión permanente en los últimos 20 años. En general, el abastecimiento se ha resuelto hasta ahora satisfactoriamente, excepto en el año 1969, y los problemas graves se van a plantear a partir de 1975-76» (pág. 446); afirmación esta última, por completo, premonitoria, ya que, como se ha indicado, en el verano de 1978, la disyuntiva fue «cierre» de Benidorm o trasvase naval desde Alicante con empleo de buques-tanque. La primera de las conclusiones de la citada Memoria no podía ser más preocupante, al señalar que «las disponibilidades presentes de aguas potables del Ayuntamiento de Benidorm, se pueden cifrar en un caudal de TREINTA Y CINCO LITROS POR SEGUNDO (35 1/s).

Sus necesidades presentes para su suficiente abastecimiento durante la temporada estival, hacen necesario un caudal continuo de TRESCIENTOS CUARENTE Y SIETE LITROS POR SEGUNDO $(347$ 1/s)», pág. 449; en suma, un déficit $(89,34)$ de casi el noventa por ciento. Con anterioridad, el 16 de octubre de 1974, el Ministerio de Gobernación había aprobado los estatutos propuestos por la Comisión Gestora y autorizado la constitución del Consorcio de Abastecimiento de Aguas de la Marina Baja; si bien la escritura pública 
de ésta no se otorgaría sino el 29 de octubre de 1977. Sería éste el marco institucional en que, bajo la dirección técnica del Ingeniero de Caminos José Ramón García Antón, recibiría imaginativa, hábil y brillante respuesta el difícil desafío hidrológico planteado en la Marina Baja.

Del profundo conocimiento que este Ingeniero, Jefe de los Servicios de Ingeniería del Ayuntamiento de Benidorm, tenía del grave problema del agua en la comarca se había hecho eco inequívoco la referida Memoria (pág. 445). Sin su valiosísima labor, continuada por su estrecho colaborador Francisco Santiango Andrés, actual Ingeniero Director del Consorcio, no es posible entender una diacronía tan compleja y amplia, cuya piedra angular es el mutuo acuerdo entre Consorcio y Comunidades de Regantes, para el intercambio de aguas regeneradas por aguas blancas. Así, el Consorcio ha logrado atender las demandas urbana y agrícola de agua a costes unitarios muy satisfactorios y competitivos, por entero asumibles para unos y otros usuarios (TORREGROSA, Mª . Teresa: La gestión del agua en la Marina Baja, 2009, págs. 234-251).

En la Marina Baja, el difícil desafío de conjugar el extraordinario desarrollo turístico y urbano de su franja litoral, desde los años sesenta, con epicentro en Benidorm, y unas disponibilidades hídricas exiguas e irregulares, ha encontrado la amplia y certera respuesta de una planificación hidrológica adecuada, que incluye mejor regulación de caudales epigeos, perfeccionamiento, sometido a criterio riguroso de sostenibilidad, de los campos de pozos existentes y adición de nuevos sondeos y, muy destacada, por sus características y consecuencias, la reutilización de aguas depuradas; asistido todo ello de conducciones generales que permiten una armónica superposición de dos sistemas independientes - los de aguas blancas y depuradas - , que funcionan al unísono, al compás del año pluviométrico e hidrológico, y constituyen la referencia más novedosa y singular del conjunto. Añadamos, por último, el recurso a los caudales del Júcar o, incluso, en caso extremo, previo acuerdo, a los de la Mancomunidad de los Canales del Taibilla, para conjurar el riesgo extremo de una sequía muy prolongada e intensa. Destaquemos, por su originalidad, algunas de las variadas infraestructuras que procuran flexibilidad excepcional a una gestión acabada y óptima del recurso. Todas estas infraestructuras hidráulicas quedan integradas en un sistema de telemedida y control gobernado desde la Estación de Bombeo del Algar, en Callosa d'En Sarriá.

Así, es de notar la instalación que bombea las emanaciones naturales de las Fuentes del Algar al embalse de Guadalest, de manera que éste, emplazado sobre el tributario, regula asimismo la principal y más regular aportación a la citada corriente principal. En el inspirado y novedoso encuadre hidrológico de conjunto, aspecto singular y descollante es la sustitución de aguas blancas para riego por residuales regeneradas; ya nos hemos referido, con anterioridad, ampliamente a sus infraestructuras, encarezcamos aquí, no obstante, dos aspectos de muy diferente naturaleza. Uno es la avanzada tecnología de la pieza maestra de este sistema de reutilización, la EDAR de Benidorm, cuyo sistema supera el terciario, y ha de conceptuarse de especialmente avanzado, ya que termina por incluir, para eliminación de partículas indeseadas, una desaladora, que proporciona un efluente de extraordinaria calidad.

Faceta asimismo relevante y original, por su condición pionera, fue el intercambio, con incentivos diversos, de agua regenerada por blanca; trueque éste que, por vía factica, precedió a la regulación legal: con carácter general, al art. 61bis de la Ley de Aguas 29/1985, añadido por la Ley 46/1999, de 13 de diciembre; convertido luego en art. 67 del Texto Refundido de la Ley de Aguas de 2001; y, de modo específico, por tratarse de aguas depuradas, al Real Decreto 1620/2007, de 7 de diciembre. En efecto, el 5 de abril de 1989 se aprobó el primer proyecto de intercambio de aguas blancas por depuradas entre el Consorcio de Aguas de la Marina Baja y la Comunidad de Regantes de Villajoyosa. Estos acuerdos, cuyo contexto inicial era de vacío legal, han recibido calificativos dispares, casi 
siempre acertados, aunque no falte la excepción; así, nada parece que se pueda objetar a los de originales, novedosos o, incluso, a la consideración de que resultan más prácticos que formalistas; pero, en modo alguno, les conviene la de «pocos ortodoxos», al tratarse de pactos o convenios nacidos, con finalidad del todo loable, del mutuo acuerdo y ajustados de buena fe. A mayor abundamiento, las disposiciones legales indicadas no hicieron, a posteriori, sino validar actuaciones cuya bondad venía acreditadas por la práctica.

Con todo, el abastecimiento de agua a las poblaciones de la Marina Baja aislado del exterior resultaría vulnerable a las prolongadas e intensas sequías que azotan esporádicamente la comarca y su entorno; así habría ocurrido en los años finales del siglo XX y primeros del actual sin los caudales del Júcar llegados, desde el hiperembalse de Alarcón, a través del Acueducto Tajo-Segura, Postrasvase, Red en Alta de la Mancomunidad de los Canales del Taibilla y Conducción Fenollar-Rabasa-Embalse de Amadorio, tras un largo y complejo recorrido. Sin desconocer que, en caso extremo, esta infraestructura podría dar acceso, previo acuerdo específico, al auxilio de la Mancomunidad de los Canales del Taibilla, no deja de ser cierto que el camino más corto e indicado es la conexión Júcar-Vinalopó, integrado el Consorcio con ese motivo en la Junta Central de Usuarios.

Sin embargo, dicha expectativa, con el cambio de toma, por decisión unilateral, de Cortes al Azud de la Marquesa, que implica también el de agua blanca por retornos, que habrán de ser regenerados, y excluyen en todo caso abastecimientos, resultaría, a la postre, fallida. De ahí la necesidad ineludible e imperiosa de una segunda toma, aguas abajo y poco distante del Azud de Antella, que recupere, parcialmente al menos, la funcionalidad originaria de la transferencia, y restablezca una solidaridad intracomunitaria dañada por una decisión tan expeditiva y unilateral del Ministerio de Medio Ambiente, en última instancia, como perjudicial para las comarcas alicantinas de Alto y Medio Vinalopó, Alacantí y Marina Baja.

Sería ése el digno ápice de un conjunto de actuaciones hidrológicas que han permitido solventar uno de los mayores desequilibrios planteados en territorio español entre disponibilidades y demandas hídricas, evidenciando cómo la existencia de las infraestructuras precisas puede permitir y propiciar acuerdos entre usuarios cuyas posturas parecían, en principio, contrapuestas e inconciliables. Con el problema hidrológico de España por resolver, estas enseñanzas quizá pudiesen extrapolarse, con provecho, al ámbito nacional, para hacer operativo y conferir verdadera eficacia al Artículo 67 del vigente Texto Refundido de la Ley de Aguas. 
